\title{
A visual history of the ozone hole: A journey to the heart of science, technology and the global environment
}

Sebastian Vincent Grevsmühl*

*Sebastian Grevsmühl is CNRS researcher at the Centre de recherches historiques, CNRS-EHESS, Paris. Email: sebastian.grevsmuhl@ehess.fr

All global environmental images imply a fundamental tension. They embrace in one way or another a global perspective on our planet, turning our attention to temperature rise, planetary circulation patterns of pollutants or ecological metabolic processes of energy and matter at a global scale. Yet despite their global appearance, these messages take their origin in highly localized socio-technical arrangements, a circumstance that opens such images to the critique that they neglect the importance of local geographies. As Hulme noted, the "view from everywhere" is by no means the "view from everyone." ${ }^{1}$

This tension is at the heart of all global environmental images, from NASA's famous Apollo photographs, to the Keeling Curve and Michael Mann's controversial "hockey stick" graph, and it guides in particular the meaning and interpretation of a large number of remotely sensed images. ${ }^{2}$ However, probably no other icons in the history of the Earth sciences tell this story better than the images associated with the famous discovery of ozone depletion published in Nature in May 1985 just over thirty years ago. ${ }^{3}$ As I will show in the following, the ozone visualizations bring together some of the key issues involved in the production and reception of global environmental

\footnotetext{
${ }^{1}$ Hulme, "Problems with Making and Governing Global Kinds of Knowledge," 558-64.

${ }^{2}$ For the telling example of rocket photography, see: Edgington, “An 'All-Seeing Flying Eye': V-2 Rockets and the Promises of Earth Photography," 363-71.

${ }^{3}$ Farman et al., "Large Losses of Total Ozone in Antarctica Reveal Seasonal ClOx/NOx Interaction," 207-10.
} 
images - such as the robustness of scientific data, the trust in images and finally the limits of the visual -, and offer important insight into the great challenges they imply.

\section{Mediating global environmental crisis}
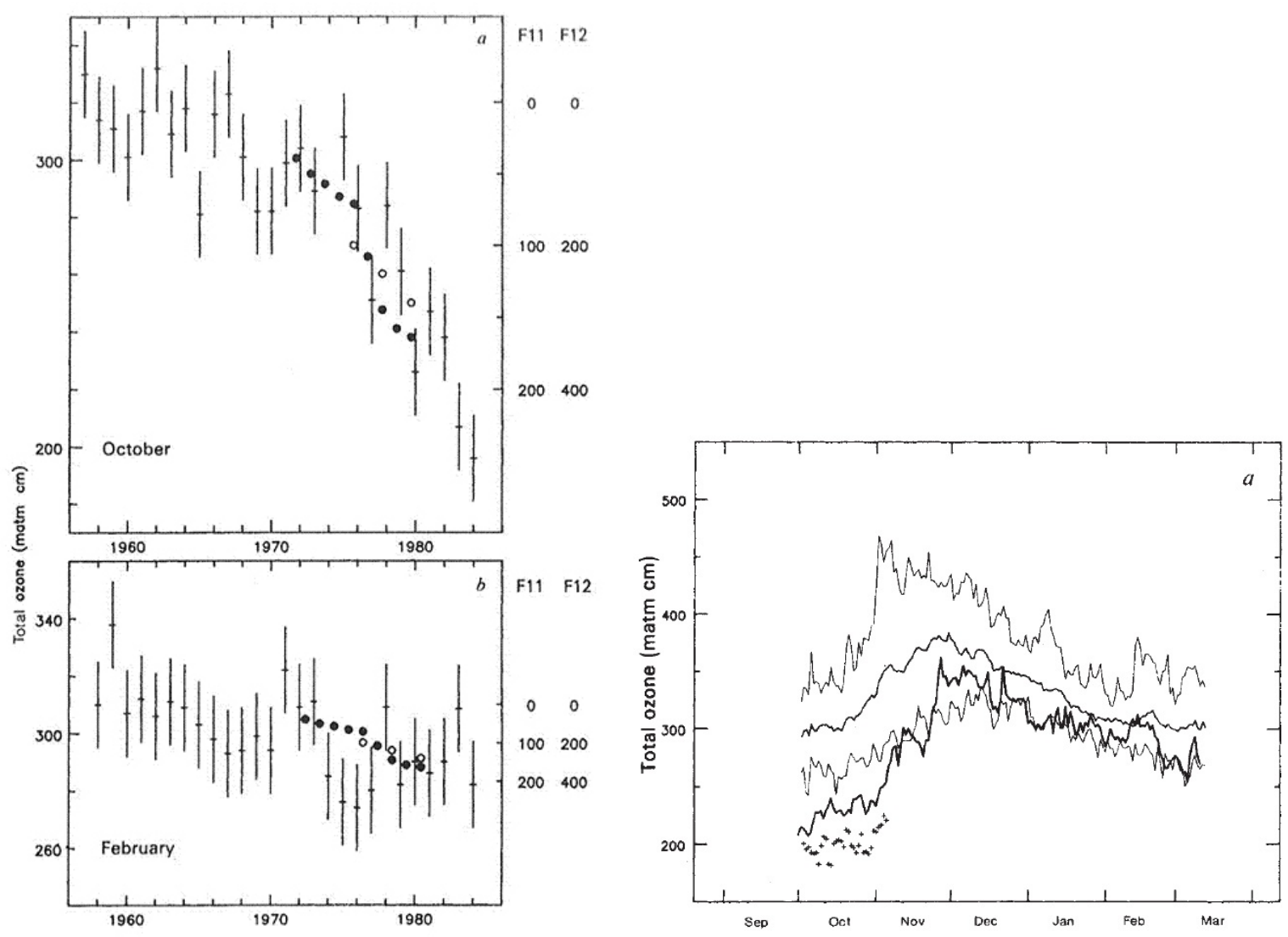

Figures 1 and 2. Left, total ozone values at Halley Bay, Antarctica. The top plot (a) shows dramatically decreasing total ozone values for the month of October; depletion phenomenon is not present during February (b, plot below). Right, total ozone at Halley Bay; thin lines show mean and extreme values for 1957-73; think line shows mean values for 1980-1984; crosses show daily ozone values for October 1984.

Credit: Farman et al., Nature (315) 1985, 207-10, both images on p.208.

Ozone imagery covers a large diversity of scientific and popular images, involving graphs, plots and computer visualizations but also drawings and cartoons which often take an imaginative approach to the "hole" in the sky metaphor (an issue which in itself 
merits close scrutiny, but my main focus will be on scientific images $\left.{ }^{4}\right)$. In scientific literature, one graph in particular stands out as it helped announce for the first time the phenomenon of annual stratospheric ozone depletion above the Antarctic continent (figure 1a). Published in the British journal Nature in 1985, the iconic graph documents plummeting ozone values measured continuously by researchers of a small research group of the British Antarctic Survey (BAS) on the Antarctic continent at Halley Bay and on Argentine Islands since the beginning of the International Geophysical Year (IGY, 1957-58).

Figure 1 is not a simple plot of raw data. Rather, the top plot shows averages of total ozone for the month of October, covering 27 years of almost continuous measurements between 1957 and 1984. Published together with graphs showing extreme values observed at Halley Bay since the International Geophysical Year held in 1957-58 (figure 2), the article offers the viewer a synoptic gaze, in the sense that the published images allow a condensed, at-a-glance overview of the entirety British ozone work conducted in Antarctica since the IGY. As I will now show in detail, far from being mere illustrations accompanying textual arguments, all images in the BAS paper were crucial scientific arguments in themselves. Indeed, according to lead author and former director of the ozone team Joseph Farman, all images were part of a carefully orchestrated, visual argumentation. In an interviews he gave, he humorously stated: "So I guess the real point about the paper was to be as concise as possible, to put enough graphs in which were moderately sensible", 5 implying that the images should play an argumentative role.

In trying to be both concise and convincing, Farman and his colleagues mobilised several visual strategies. First, visual comparison was key to their argumentation. Figure

\footnotetext{
${ }^{4}$ For a recent historical analysis of the "ozone hole" metaphor, see: Grevsmühl, "Revisiting the 'Ozone Hole' Metaphor."

${ }^{5}$ Farman, “Life Story Interview," transcript, 238.
} 
1 allows comparing mean ozone values for October (top plot) and February (bottom plot) for all observing seasons since the IGY. The sober visual presentation makes it relatively straightforward to spot in the top graph a "decreasing" trend especially throughout the 1980s (despite some variability), in particular when compared with the bottom graph, where the severe depletion phenomenon is absent.

However, what makes the low October values special cannot be grasped from the two graphs in figure 1 alone. This is addressed in Figure 2, through its mode of comparison. Figure 2 appeared in the published version directly next to figure 1 and introduced what Farman calls a "new method of presentation," a method he "invented" specifically for the paper. ${ }^{6}$ The top and third line (counting from the top) show all extreme ozone values recorded at Halley Bay between 1957 and 1973, providing as Farman states, an "envelope" for all the other readings. And since the more recent October values fall well outside of this envelope - be it the daily recordings of October 1984 represented now by crosses, or the mean ozone values for 1980-1984 shown in the lowest line - the informed reader has all the important information at hand to conclude that the recent ozone measurements "are unprecedented [low] values." ${ }^{7}$

A second key strategy employed by the authors, and closely related to comparison, is visual simplification. The publishing format played an important role since the researchers wanted the article to be published with minimal delay, and thus decided to submit their paper as a "letter" to Nature (as opposed to a full-length research article), spanning only four pages in length. According to Farman, "the main thought was to make it as simple and clear as one possibly can."8 However, more importantly, also all the images of the paper were designed with this simplification strategy in mind. As Farman

\footnotetext{
6 Ibid., 238.

7 Ibid., 285.

8 Ibid., 286.
} 
states, even a lay observer should be able to identify the key message by simply looking at the images, so that “you don't really need to start talking about distributions and frequency distributions and such like things; it's perfectly obvious what's going on."9

To be sure, a now abundant literature in science and technology studies has shown that scientific images never speak for themselves, as they always rely necessarily on normative elements and social factors embedded in their context of production. ${ }^{10}$ Nonetheless, Farman's view expresses a typical strategy in science: images can be mobilised as arguments, and if presented as "simple" and "convincing" as possible, they can even help silence critical voices. ${ }^{11}$ When it is "obvious" that the latest ozone measurements are the lowest on record - and all images try to make this point in a more or less "simple" way, with relatively few visual elements to be analysed - the reader can move on to possible explanations for the phenomenon (instead of rejecting the phenomenon per se as irrelevant or flawed).

Finally, a third noteworthy strategy employed is visual dramatization and exaggeration. The first plot shown in figure 1a makes a compelling visual argument about rapid ozone depletion since the late 1970s, also because the axis of abscissae is relatively short in length. One of the initial drafts for this graph prepared by BAS researcher Jonathan Shanklin employed a far longer and wider abscissae, giving the impression of a "smoother" decline because the values were separated from one another by larger spacing. The compression of the year axis of figure 1 in the published version

\footnotetext{
9 Ibid., 285-6.

10 See for instance : Lynch and Woolgar, Representation in Scientific Practice; Baigrie, Picturing Knowledge; Jones and Galison, Picturing Science, Producing Art; Coopmans, Vertesi, Lynch and Woolgar, Representation in Scientific Practice Revisited.

${ }^{11}$ Aspect developed in detail in: Merchant, "He didn't go round the conference circuit talking about it'," in Silences of Science, eds. Mellor and Webster, 39.
} 
helped therefore dramatize visually the ozone depletion effect with a far "steeper," rapid decline. ${ }^{12}$

Considered together, these three visual strategies demonstrate that BAS' ozone team put great effort into communicating their findings in a concise and visually compelling way. The images, moreover, formed an important part of the scientific argument, speaking potentially not only to the scientific community but also the lay public, although the scientific impact was, as we will see below, more successful. The graphs are analogous with other well-known global environmental icons of the Cold War period, such as the famous Keeling Curve that documents rising CO2 levels at Mauna Loa, Hawaii, also measured since the IGY. ${ }^{13}$ This becomes particularly evident when considering the actual data used in constructing these images. Although such comparison leads away from the ozone images, a broader discussion on images and data is necessary to better understand how trust in images is generated in science.

\section{On images and data}

In addition to the visual strategies discussed above, the ozone images, and in fact all global environmental images, depend crucially on the quality of the data that goes into them. This means that as with any scientific image, they can either convey very powerful explanations or reveal purely trivial aspects of the geophysical or environmental phenomena for which they want to account. Their impact and success rely in many ways

\footnotetext{
${ }^{12}$ See: Shanklin personal archives, Cambridge, UK.

${ }^{13}$ On the Keeling curve, see: Howe, "This is Nature; This is Un-Nature: Reading the Keeling Curve," 28693.
} 
on how trust in the data is generated. ${ }^{14}$ Two related aspects might account for this: robustness and data friction. ${ }^{15}$

In the ozone case, the continuity and robustness of the ozone measurements database played a key role in the scientific acceptance of the graph's important message. First, one key feature of the ozone plots is that each data point relates to all others in a straightforward way. This visual continuity, as expressed, for instance, by the continuous thin lines in figure 2 stretching all the way back to 1957, is an important historical indicator. It proves that British ozone research was taken seriously in the past, that the work in Antarctica was financed and carried out on a regular basis since IGY (even though there were some funding issues from time to time), and most importantly, that no significant gaps are apparent. Although representing discrete data points, figure 1a also shows a continuous data set, with data points for every single year since 1957.

This historical continuity points also to the future, creating the strong political argument not to cut funding as this would endanger the scientific continuity of the data records. Indeed, today continuous ozone monitoring in Antarctica, even though at a reduced level, is still a major activity of BAS' ozone research group led today by Jonathan Shanklin.

Second, the small research team of BAS knew how to build up trust in their data and hence their images with the help of regular instrument calibrations but also rigorous methodological consistency. The instrumental backbone of the ozone network, the Dobson spectrophotometer, named after its British inventor who produced the first total ozone measurements in Oxford during the 1920s, underwent few changes throughout

\footnotetext{
${ }^{14}$ See for instance the influential study by Porter, Trust in Numbers. For trust in images, see for example: Daston and Galison, Objectivity.

${ }^{15}$ Both notions have received considerable scholarly attention in the past. Robustness is discussed in detail in: Nowotny, Scott and Gibbons, Re-Thinking Science; the concept of data friction is adopted from Edwards, A Vast Machine, a useful description of problems that arise during weather and climate data collection and their integration into global views.
} 
its history. ${ }^{16}$ There was, in other words, very little friction involved, allowing researchers to create a highly robust dataset - without the necessity of making data of different instrumental origins compatible (as it is often the case nowadays in the earth sciences) - and to speak thus with authority on Antarctic stratospheric ozone. In the published ozone images, we can see this for instance in figure 1a, where all data points are represented with the always same margin of error (the brackets around each data point show the margin of error).

In the Earth sciences, instrumental and methodological robustness is in other words crucial for the visual arguments one intends to make. Many other examples could be invoked where this process worked rather well. The so-called Keeling Curve, as Howe has shown, is a very good case in point. ${ }^{17}$ It visualises the monthly record of carbon dioxide at Mauna Loa's observatory (Hawaii), showing a continuous increase in concentration from around 314ppm in 1957 to almost 410ppm in 2017. This data has become one of the most persuasive environmental bases for climate change, mainly because it relies on a similarly robust data set as stratospheric ozone in Antarctica, with almost continuous measurements stretching back to the IGY. In the case of other iconic graphs, data friction was a major issue, as in the case of Michael Mann's early "hockey stick" graphs, reconstituting historical temperatures for several centuries. Since instrumental records reach back only to mid-19th century, Mann had to mobilise other sources (so-called proxy's) in order to reconstitute past climates. The severest critique

\footnotetext{
${ }^{16}$ One scientific report in particular accounts for the robustness of BAS' ozone data: Farman and Hamilton, Measurements of Atmospheric Ozone at the Argentine Islands and Halley Bay, 1957-1972.

${ }^{17}$ Howe, "This is Nature; This is Un-Nature: Reading the Keeling Curve," 286-93.
} 
of his work focused on the issue of data friction and the uncertainty attached to the data represented in his graphs. ${ }^{18}$

\section{On the limits of images}

Although the ozone images were carefully designed to be convincing (according to their authors), there are nonetheless important limits to the visual. Quite ironically, the British ozone graph in figure 1a included a visual correlation between rising CFC levels (the most widespread CFC's F11 and F12 ${ }^{19}$, represented here by black and white dots with amounts increasing down the figure) and plummeting stratospheric ozone values, an assumption that was at the time reasonable, yet also speculative for the Antarctic continent. Indeed, back in 1985, little was known on the exact mechanism causing ozone depletion in the Antarctic stratosphere, not to mention the fundamental role of polar stratospheric clouds, which was only suggested in 1986 and later confirmed during NASA's field missions. ${ }^{20}$ The visual correlation of two separate events (such as in this case Antarctic ozone depletion and CFC concentrations) does not prove anything per se and scholars interested in statistical graphics often mock this type of reasoning by correlating the most improbable phenomena. ${ }^{21}$

This leads to a second crucial point that pertains directly to BAS' ozone imagery. Although the authors put considerable effort in preparing the images of their findings, there is little evidence that the images spoke immediately to the lay public as intended by Farman who believed the images would speak for themselves. Although the scientific community reacted promptly, relatively few news outlets seem to have taken notice of

\footnotetext{
18 The "hockey stick" controversy is documented here: http://www.realclimate.org/index.php/archives/2010/07/the-montford-delusion/ (accessed on September 19, 2017).

${ }^{19} \mathrm{~F} 11$ and F12 were used as aerosol propellants and in air-conditioners.

20 Solomon, "Stratospheric Ozone Depletion: A Review of Concepts and History," 275-316.

21 Tufte, Visual Display of Quantitative Information, 15.
} 
the British ozone work, and even less in the depletion graphs. Indeed, it is only in retrospect, with several anniversaries celebrated by Nature on ground breaking environmental papers, with the publication of several popular historical accounts of the ozone crisis, and especially with the recent death of Farman, that the British Antarctic Survey images finally received widespread attention..$^{22}$

This initial lack of impact can (at least partly) be explained by the actual nature of the graphs. As a graph, figure 1 could not show a global perspective on the Antarctic atmosphere-it, rather, reflected the local field perspective of BAS' research in Antarctica. After all, the British Antarctic Survey was running measurement campaigns at only two places in the Antarctic region and were lucky that Halley Bay was situated almost at the centre of what would become known as the annual "ozone hole" of the early 1980 s. $^{23}$ Indeed, as I will show in the following, it was only NASA's global satellite perspective, first provided by the Total Ozone Mapping Spectrometer (TOMS) on the Nimbus 7 satellite, that helped dramatically shift perspective to a global view on the Southern hemisphere. This shift proved crucial because in order to find solutions for this severe environmental threat, a truly global, visual perspective was needed.

\section{Adopting a global perspective}

NASA was quick in picking up on the ozone depletion alert issued by the British Antarctic Survey and once again, images (as depicted in figures 3 and 4) played a decisive role in communicating the findings, as they helped transform a local depletion phenomenon into a global environmental threat. Several visual elements accounted for this powerful global shift.

\footnotetext{
22 Stolarski, “A Hole in Earth's Shield," in A Century of Nature, ed. Garwin and Lincoln, 283-89.

${ }^{23}$ Shanklin, interview with the author.
} 

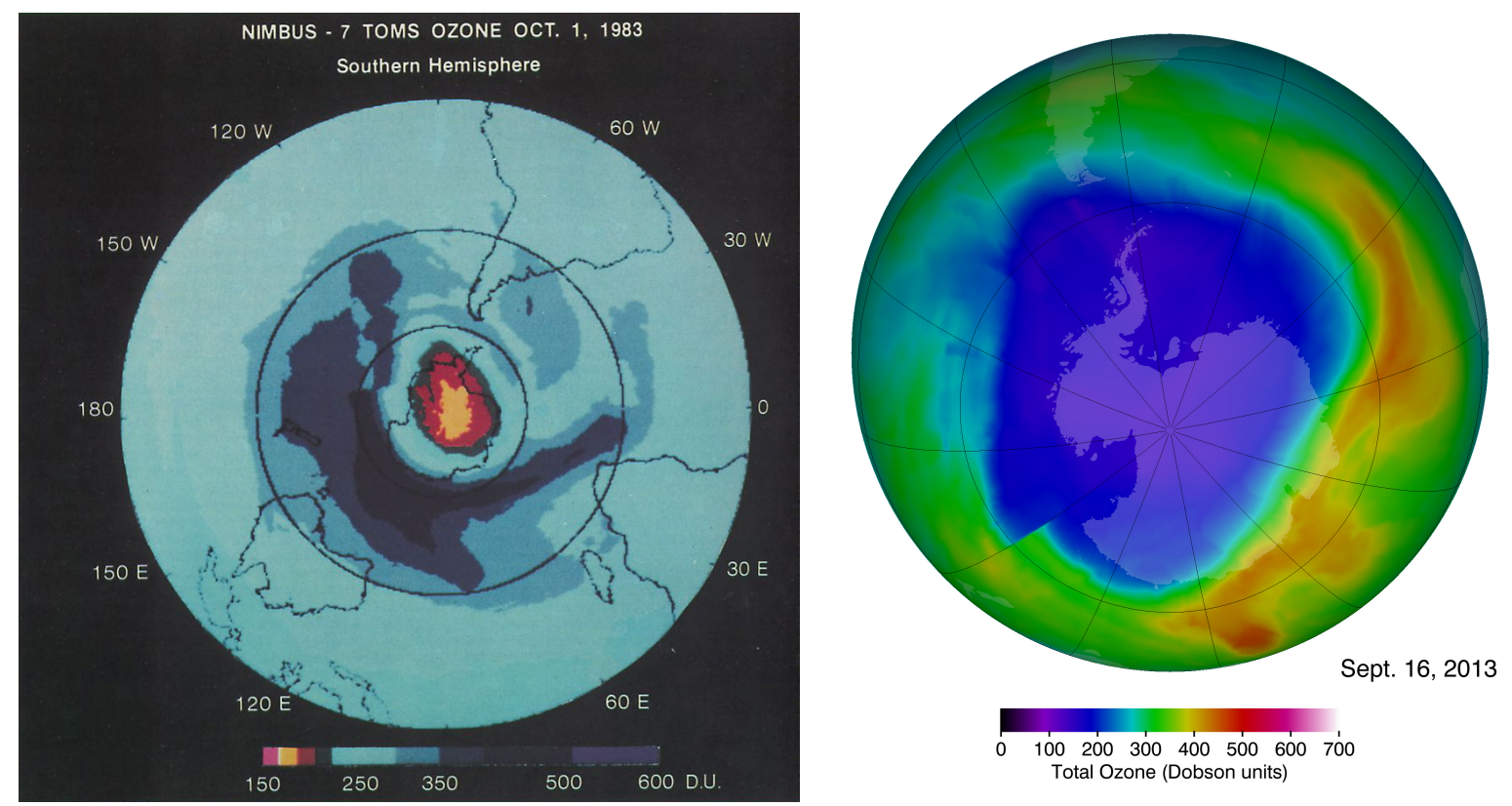

Figures 3 and 4: Left, NASA's first published TOMS data visualization showing dramatically low ozone values (in yellow and red) for October 1, 1983 above the Antarctic continent. Right, contemporary visualization showing the annual "ozone hole" on September 16, 2013 in blue and purple. Credit: NASA, GSFC.

As I have argued, the satellite images provided a bird's eye view on the entire Southern hemisphere, integrating about 140.000 daily satellite measurements into a single image. ${ }^{24}$ This was particularly effective because several visual strategies were deployed. First, NASA scientists at the Goddard Space Flight Center (GSFC) introduced contour lines (a tool best known from topographic maps), which allowed for visually emphasizing data points of equal value. In choosing values at different data intervals, such visualizations allowed viewers to spatially distinguish differences in ozone concentration, and thus to speak of an "ozone hole." Indeed, the first news report that introduced in late 1985 the famous "ozone hole" metaphor to a large public, used a

\footnotetext{
${ }^{24}$ See: Grevsmühl, "The Creation of Global Imaginaries," 29-53.
} 
simplified version of these early contour images to point the reader to a glaring black "hole" above the Antarctic continent. ${ }^{25}$

This visual strategy was conjoined with another: to colour-code these global views, using so-called "false colours." These were assigned to specific ozone concentrations, ranging in the earliest depictions (see figure 3) from light blue (high ozone values) to red and yellow (severe ozone depletion). Today most common renditions (see figure 4), use a different colour palette: from red and pink (high ozone values) to purple and blue (severe ozone depletion). Enabled by the satellite perspective, this visual effect was highly convincing, including its implied assumption of continuous measurement, not only in time but also space. ${ }^{26}$ Such imagery could be animated, resulting in video atlases composed by combining large sets of static images (a technique still in use today). Videos were critical in showing the importance of seasonal dynamic as well as the annual widening and closing of the "hole" over several decades. ${ }^{27}$

This new framing of the ozone hole story from late 1985 onwards as global environmental threat had a lasting impact. NASA's visualizations (which all can be distributed freely without copyright restrictions) provided seemingly indisputable evidence of an otherwise invisible global environmental threat, enabling public appreciation of the global impact of industrial pollutants. The ozone visualizations, especially when mapped on a more globe-like projection as shown in figure 4, thus fed into common visual themes of whole earth imagery, famously represented by the iconic "Blue marble" (Apollo 17, 1972), forcing the Western gaze to turn attention to regions of

\footnotetext{
25 Sullivan, "Low Ozone Level Found Above Antarctica," B21.

26 Grevsmühl, "The Creation of Global Imaginaries," 44.

27 Goddard Space Flight Center, Animated Atlas of TOMS Ozone: 1978-1988. Today, NASA's “Ozone Watch" Page distributes all relevant ozone images and videos: https://ozonewatch.gsfc.nasa.gov/ (accessed on September 19, 2017).
} 
the planet that were mostly excluded from the dominant geographical imagination. ${ }^{28}$ The global implications were reinforced by Western media that frequently portrayed the "hole" in the sky as part of an ongoing global environmental crisis, stretching from rainforest destruction to global warming, making an effective public case for our planet's ecological limits. ${ }^{29}$

As Maher has pointed out recently, the huge success of NASA's ozone imagery in both scientific and lay circles inspired NASA to institutionalise this new form of powerful environmental storytelling, in particular with the creation, in 1988, of the Scientific Visualization Studio at GSFC. ${ }^{30}$ In merging cultural images of the global environment and global Earth observation data, NASA provided a new common ground and a shared language for the environmental movement and earth scientists alike.

However, despite their success, global environmental images such as the ozone "hole" beg some important questions about scale and power, in particular when considering the relationship between the global and the local, a point raised at the beginning of this essay.

\section{For an inquiry into global environmental images}

Today, in the eyes of ozone researchers and policy makers, there is no doubt that the ozone hole case is a unique global environmental success story and NASA's satellite visualizations played an important part in placing this environmental threat on the

\footnotetext{
${ }^{28}$ Cosgrove, "Contested Global Visions: One-World, Whole-Earth, and the Apollo Space Photographs," 27094; see also: Jasanoff, "Image and Imagination," 309-37; Grevsmühl, La Terre vue d'en haut, ch.6; Höhler, Spaceship Earth in the Environmental Age, ch.1.

${ }^{29}$ For an American perspective, see for example: Dunaway, Seeing Green, 189 and 199. In Germany, the "ozone hole" frequently made it into the influential news weekly Der Spiegel, it was part of many environmental scare stories in 1986 (such as an issue on the "climate crisis") and even made it on the front cover in August 1987.

${ }^{30}$ Maher, Apollo in the Age of Aquarius, 128-36.
} 
public and international political agendas. ${ }^{31}$ However, as products of globalised, planetary-scale knowledge, ozone "hole" visualizations, as do all global environmental images, come with some major drawbacks.

As argued above, in order to become meaningful in everyday living, planetary perspectives need to be accompanied by powerful storytelling. In so doing, NASA's planetary views were far more successful in the public sphere than BAS' local graphs, mainly because they effectively linked global satellite data with existing cultural conceptions of whole earth, supplemented by a dramatic environmental metaphor, the ozone "hole." As a shared language between different communities and publics, it promoted however also a very specific worldview not shared by everyone. Whole earth imaginings, as promoted by big science institutions such as NASA, promote fundamentally Western values of science and nature, begging for instance the important question about who has access to the large-scale environmental surveillance infrastructures that grew mostly out of Cold War efforts to monitor the dynamics of the earth system. ${ }^{32}$

Moreover, crucial elements of the ozone story were only addressed within the story making process but not by the imagery itself. Although NASA's ozone imagery skilfully drew our attention to a region largely neglected beforehand - the Antarctic region and, in a more general way, the Southern hemisphere - very few images distributed by the space agency addressed the underlying geographies of power. Indeed, whereas one of the BAS-produced ozone graphs tentatively included chlorofluorocarbon concentrations (figure 1a), none of NASA's visualisations included the pollutants or the highly uneven geographies of emission locations that were identified as being at the very source of the

\footnotetext{
${ }^{31}$ By mid-century, ozone values are expected to return to "normal:" WMO, Scientific Assessment of Ozone Depletion: 2014.

${ }^{32}$ McNeill and Unger, Environmental Histories of the Cold War; Hamblin, Arming Mother Nature; Turchetti and Roberts, The Surveillance Imperative.
} 
ozone crisis. Critically questioning the images and the underlying geographies become particularly important when global environmental images are mobilised as objects of governance because this raises important questions about who owns and controls the future.

Global views on our environment thus clearly contribute to a better scientific understanding of global processes, but they also raise many questions on how exactly images, and the technologies that bring them to life, can impact society. These questions are certainly not simple ones, yet they clearly call for a sustained, historically informed, interdisciplinary inquiry into the meaning-making of global environmental images and their associated knowledge infrastructures.

\section{Acknowledgments}

I would like to thank Jennifer Tucker and Martin Collins for their support, guidance and helpful suggestions, as well as an anonymous reviewer for the valuable critical comments.

\section{References}

Baigrie, Brian. Ed. Picturing Knowledge: Historical and Philosophical Problems Concerning the Use of Art in Science. Toronto: University of Toronto Press, 1996.

Coopmans, Catelijne, Janet Vertesi, Michael Lynch and Steve Woolgar, ed. Representation in Scientific Practice Revisited. Cambridge: MIT Press, 2014.

Cosgrove, Denis. "Contested Global Visions: One-World, Whole-Earth, and the Apollo Space Photographs." Annals of the Association of American Geographers 84 (1994): 270-94.

Daston, Lorraine and Peter Galison. Objectivity. New York: Zone Books, 2010.

Dunaway, Finis. Seeing Green: The Use and Abuse of American Environmental Images. Chicago: University of Chicago Press, 2015.

Edgington, Paul, “An 'All-Seeing Flying Eye': V-2 Rockets and the Promises of Earth Photography." History and Technology 28 (2002): 363-71.

Edwards, Paul. A Vast Machine. Cambridge: MIT Press, 2010. 
Sebastian V. Grevsmühl, A visual history of the ozone hole: A journey to the heart of science, technology and the global environment, History and Technology, vol. 33, no. 3, 2017, p.333-344.

Farman, Joseph, Brian Gardiner, and Jonathan Shanklin, "Large Losses of Total Ozone in Antarctica Reveal Seasonal ClOx/NOx Interaction.” Nature 315 (1985): 207-10.

Farman, Joseph. “Life Story Interview for 'An Oral History of British Science,' recording and transcript, C1379/07, 2010, 1-359.

Farman, Joseph and Richard Hamilton. Measurements of Atmospheric Ozone at the Argentine Islands and Halley Bay, 1957-1972. Cambridge: British Antarctic Survey, 1975.

Goddard Space Flight Center. Animated Atlas of TOMS Ozone: 1978-1988. VHS (NTSC), 40min., NSSDC Photo Lab, 1989.

Goddard Space Flight Center. Ozone Watch Page: (accessed on September 19, 2017).

Grevsmühl, Sebastian. La Terre vue d'en haut: l'invention de l'environnement global. Paris: Seuil, 2014.

Grevsmühl, Sebastian. “The Creation of Global Imaginaries,” In Image Politics of Climate Change, ed. Birgit Schneider, 29-53. Berlin: Transcript, 2014.

Grevsmühl, Sebastian. "Revisiting the 'Ozone Hole' Metaphor: From Observational Window to Global Environmental Threat,” Environmental Communication, forthcoming, doi:10.1080/17524032.2017.1371052.

Hamblin, Jacob. Arming Mother Nature: The Birth of Catastrophic Environmentalism. Oxford: Oxford University Press, 2013.

Höhler, Sabine. Spaceship Earth in the Environmental Age, 1960-1990. London: Pickering \& Chatto, 2015.

Howe, Joshua. "This is Nature; This is Un-Nature: Reading the Keeling Curve." Environmental History 20 (2015): 286-93.

Hulme, Mike. "Problems with Making and Governing Global Kinds of Knowledge." Global Environmental Change 20 (2010): 558-64.

Jasanoff, Sheila. "Image and Imagination: The Formation of Global Environmental Consciousness." In Changing the Atmosphere: Expert Knowledge and Environmental Governance, ed. Clark Miller and Paul Edwards, 309-37. Cambridge: MIT Press, 2001.

Jones, Caroline and Peter Galison, ed. Picturing Science, Producing Art. London: Routledge, 1998.

Lynch, Michael and Steve Woolgar, ed. Representation in Scientific Practice. Cambridge: MIT Press, 1990.

Maher, Neil. Apollo in the Age of Aquarius. Cambridge: Harvard University Press, 2017.

McNeill, J.R. and Corinna Unger, ed. Environmental Histories of the Cold War. Cambridge: Cambridge University Press, 2013.

Merchant, Paul "'He didn't go round the conference circuit talking about it'." In Silences of Science, ed. Felicity Mellor and Stephen Webster, 31-47. London: Routledge, 2017.

Nowotny, Helga, Peter Scott, and Michael Gibbons. Re-Thinking Science. Cambridge: Polity, 2001.

Porter, Theodore. Trust in Numbers: The Pursuit of Objectivity in Science and Public Life. Princeton: Princeton University Press, 1995.

RealClimate Blog. http://www.realclimate.org/index.php/archives/2010/07/the-montford-delusion/ (accessed on September 19, 2017). 
Sebastian V. Grevsmühl, A visual history of the ozone hole: A journey to the heart of science, technology and the global environment, History and Technology, vol. 33, no. 3, 2017, p.333-344.

Solomon, Susan. "Stratospheric Ozone Depletion: A Review of Concepts and History." Reviews of Geophysics 37 (1999): 275-316.

Stolarski, Richard. “A Hole in Earth's Shield." In A Century of Nature, ed. Laura Garwin and Tim Lincoln, 283-89. Chicago: University of Chicago Press, 2003.

Sullivan, Walter. “Low Ozone Level Found Above Antarctica." New York Times (7 November 1985): B21.

Tufte, Edward. Visual Display of Quantitative Information. Cheshire: Graphics Press, 1983.

Turchetti, Simone and Peder Roberts, ed. The Survillance Imperative. New York: Palgrave, 2014.

WMO. Scientific Assessment of Ozone Depletion: 2014. Geneva: WMO, 2014. 